\title{
Phytochemical analysis, antioxidant and cytotoxic activities of Dryopteris ramosa.
}

\author{
Baloch R*, Uzair M, Chauhdary BA, Hayat MM, Alamgir M \\ Pharmaceutical Chemistry, Faculty of Pharmacy, Bahauddin Zakariya University, Multan, Pakistan
}

\begin{abstract}
Objective: The aim of present study was to evaluate phytochemical, cytotoxic and antioxidant potential of dichloromethane and methanol extracts of Dryopteris ramosa (Hope) C. Chr. belongs to family Dryopteridaceae. The plant is traditionally used as anthelminthic, diuretic, antibacterial, astringent and as tonic for various stomach and intestinal problems.

Method: The phytochemical potential, total phenol, flavonoid and alkaloid contents of Dryopteris ramosa were determined for the first time. Plant was subjected to Brine shrimp lethality and DPPH inhibition assay was done. Identification and quantification of various phenolic content by was done HPLC.

Results: Phytochemical analysis revealed that flavonoids, terpenoids, cardiac glycosides, alkaloids and saponins were present in the plant while tannins were absent. The results depicted high in vitro cytotoxic effect by dichloromethane extract with a $\mathrm{LD50} 0.6903 \mu \mathrm{l} / \mathrm{ml}$ as standardized with Etoposide with LD50 of $7.4625 \mu \mathrm{l} / \mathrm{ml}$. The methanol extract showed the strong DPPH scavenging activity with $72.76 \pm 1.52 \%$ inhibition as compared to the dichloromethane extract with $55.37 \pm \mathbf{3 . 0 5 5} \%$ inhibition. The high phenol content was found in methanol extract having $199.2 \pm 4.50(\mathrm{mg}$ of GA/g of extract). HPLC analysis showed the presence of various phenol compounds (Gallic acid, quercetin, caffeic aid, vanillic acid, cinnamic acid etc.) with their relevant concentration, in the plant. The dichloromethane extract exhibited high flavonoid content $73.02 \pm 1.00$ ( $\mathrm{mg}$ of RE/g of extract). Alkaloidal content was highest in dichloromethane extract with $29.73 \pm 4.04$ ( $\mathrm{mg}$ of $\mathrm{AE} / \mathrm{g}$ of extract).
\end{abstract}

Keywords: Antioxidant, Cytotoxic, Dryopteris ramosa, HPLC, Phytochemical analysis.

Accepted on july 29, 2019

\section{Introduction}

Oxidative stress caused by free radicals can cause serious damage to the important cellular macromolecules like DNA and protein [1]. These toxic effects of free radicals have drawn the researcher's attention to the significance of antioxidants in the prevention and treatment of various ailments [2]. Many studies have been done on the natural sources to produce natural antioxidants with lower cytotoxic profiles [3].

Cancer, a genetic disease, is mainly caused due to genetic instability involving variations in tumor suppressor genes and in oncogenes which causes expression of abnormal proteins engaged in the stimulation of cell proliferation and its survival [4]. Previous studies have proved that free radicals have the key role in the development of cancer [5].

Secondary metabolites, like phenols, alkaloids, flavonoids and tannins, widely distributed in plants, possess multiple biological effects including free radical scavenging activities, anti-inflammatory, antioxidant and anti-carcinogenic effects [6]. Various studies have been done on herbal plants, fruits and vegetables which indicated the presence of antioxidants in the form of phenolic compounds, flavonoids, proanthocyanidins and tannins [7].

Contrariwise, to the best of our understanding, various medicinal plants used as vernacular medicine still require scientific attention and D. ramosa is one of them. Plant is traditionally known as "Pakha". D. ramosa is used as diuretic, astringent and febrifuge [8]. Plant is also used as tonic for various stomach and intestinal problems [9]. Young leaves are collected in March-May as a vegetable and are used as spinach against gastric ulcer, constipation and as aphrodisiac [10]. Rhizome has anti-bacterial and anthelminthic potential [11]. In the present research dichloromethane and methanol extracts of D. ramosa were evaluated for their phytochemical potential, cytotoxic and antibacterial capacities.

\section{Method}

\section{Plant collection and extraction}

The plant D. ramosa was collected from place Nathia gali, District Abbottabad, Khyber Pakhtunkhwa province, Pakistan. Plant was identified by Assistant Professor Dr. Zafarullah 
Zafar, Institute of Pure Applied Biology, Bahauddin Zakariya University, Multan. In order to obtain effective extracts plant was dried in shade for about 15 days. Dried plant was ground and weighed. Extraction of plant done was by the process of maceration. The weighed amount of ground plant was kept in extraction bottle and then pre-determined volume of dichloromethane was added to it. For the purpose of maximum extraction bottle was placed on ultrasonic bath. After 24 hours, filtration was carried out. Same process was done thrice with dichloromethane. Further, marc of plant was extracted with methanol in the same manner. The dichloromethane and methanol extracts were prepared using rotary evaporator. The dichloromethane (100.2 g) and methanol (120.9 g) extracts were collected in separate sample bottles and designated with codes as DRD and DRM respectively.

\section{Preliminary phytochemical analysis}

Chemical tests for identification of secondary metabolites: The dry powder of whole plant D. ramosa was evaluated for the presence of secondary metabolites (like alkaloids, saponins, cardiac glycosides, etc.) according to the standard protocol methods. In these tests formation of turbidity or development of color is generally involved. An authentic specimen is always used to compare the obtained color. While in case of precipitation reaction turbidity formation is compared with the control. Control is always without drug merely containing reagent. These tests can be applied to the extracts as well as isolated constituents [12].

Determination of total phenol content: Total phenolic content was determined using Folin-Ciocalteu colorimetric method. Gallic acid was used as the standard and the results were expressed in terms of equivalent (GAE) per gram of sample. Various concentrations of gallic acid $(0.01-0.1 \mathrm{mg} / \mathrm{ml})$ were prepared using methanol as solvent. Fractions of $0.5 \mathrm{ml}$ of the sample and the standard were taken. Two $\mathrm{ml}$ of FolinCiocalteu reagent was added to these fractions and the reaction was initiated by the addition of $(7.5 \% \mathrm{w} / \mathrm{v})$ sodium carbonate solution. The tubes were then covered with silver foils and were allowed to incubate for about thirty minutes at room temperature. Absorbance was measured at $765 \mathrm{~nm}$ while using methanol as blank. All the samples were processed in three repetitions. The total phenolic content of the extract was determined by the help of standard curve of Gallic Acid. FolinCiocalteu is a sensitive reagent that reduces compounds including polyphenols, hence producing a blue color upon reaction. This blue color was measured [13].

Determination of total flavonoid content: Aluminum chloride colorimetric assay was used to determine the flavonoid content of the plant extract in this study. Fractions of $0.5 \mathrm{ml}$ of the sample and the standard, Rutin, $(0.01-1.0 \mathrm{mg} / \mathrm{ml})$ of were taken. Two $\mathrm{ml}$ of distilled water and $0.15 \mathrm{ml}$ of sodium nitrite $(5 \% \mathrm{NaNO} 2, \mathrm{w} / \mathrm{v})$ solution was added to the fractions and then mixed. To this, $10 \%$ solution of $\mathrm{AlCl} 3 \mathrm{w} / \mathrm{v}$, was added after six minutes. The prepared solution was allowed to stand for more six minutes and then $2 \mathrm{ml}$ of $(4 \% \mathrm{NaOH} \mathrm{w} / \mathrm{v})$ sodium hydroxide solution was added to it. Dist. water was added immediately to make the final volume $5 \mathrm{ml}$. This mixture was allowed to stand for $15 \mathrm{~min}$. Absorbance of prepared mixtures was taken at $510 \mathrm{~nm}$. Calibration curve of Rutin was used to determine total flavonoid content and then TFC was expressed in terms of mg Rutin equivalent per gram of sample. Same procedure was performed thrice [14].

Determination of total alkaloid content: $1 \mathrm{mg}$ of plant extract was taken and dissolved in Dimethyl Sulfoxide (DMSO). $1.0 \mathrm{ml}$ of $2 \mathrm{~N} \mathrm{HCl}$ was added to it and was then filtered. After filtration, filtrate was transferred to separating funnel. $5 \mathrm{ml}$ of bromocresol green solution and $5 \mathrm{ml}$ of phosphate buffer, was added to the separating funnel. This mixture was vigorously shaken by adding 1,2,3 and $4 \mathrm{ml}$ chloroform. Later, it was collected in $10 \mathrm{ml}$ volumetric flask and was diluted with chloroform to make the volume. Reference standard solutions of atropine (20, 40, 60, 80 and $100 \mu \mathrm{g} / \mathrm{ml})$ were prepared likewise. The absorbance of test and standard solutions was measured at $470 \mathrm{~nm}$ in UVSpectrophotometer and the total alkaloid content was expressed as $\mathrm{mg}$ of $\mathrm{AE} / \mathrm{g}$ of extract [15].

Identification and quantification of phenol contents by HPLC: Samples $(10 \mu \mathrm{l})$ were analyzed by HPLC (Shimadzu Model 10A) pump equipped with a UV-Visible detector, 280 $\mathrm{nm}$ using a Shim-Pack CLC-ODS (C-18) column, $25 \mathrm{~cm} \times 4.6$ $\mathrm{cm} \times 5 \mu \mathrm{m}$. Solvents used were A water-AA $(94: 6, \mathrm{pH}=2.27)$ and $\mathrm{B}$ acetonitrile $100 \%$ at a flow rate of $1 \mathrm{ml} / \mathrm{min}$. All the solvents used were of HPLC grade. The phenolic compounds were identified by chromatographic comparison with authentic markers using standards including quercitin, gallic acid, vitamin $\mathrm{C}$, vanillic acid, m-coumaric acid, sinapic acid, ferulic acid, caffeic acid, syringic acid, 4-OH-3 methoxy benzoic acid, trans-4-OH-3-methoxy cinamic acid, chlorogenic acid and chromatotropic acid. Phenolic compounds were quantified by peak area using authentic standards.

\section{Biological activities}

Brine shrimp lethality assay: Artificial sea water was prepared by mixing $3.8 \mathrm{~g}$ of sea salt $/ 1000 \mathrm{ml}$ of water. It was then filtered and poured in an unevenly divided large tank, eggs of the shrimp were then kept in bigger part of the tank and was later covered with aluminium foil. Eggs then hatched in the tank and larvae started to move in compartment. Temperature of the larvae's tank was adjusted at $37^{\circ} \mathrm{C}$ for the maturity and growth of the larvae. Concentration of 1000, 100, 10 micrograms per milliliters were prepared in the vials for testing and in three replicates from every dilution to make total of nine vials, to the $20 \mathrm{mg}$ of sample. After that $2 \mathrm{ml}$ of organic solvent was taken and from the solution 500, 50, $5 \mu$ l was used in same order. Solvents were allowed to evaporate under nitrogen by applying high vaccum for about thirty minutes. After the two days 10 shrimps were added to the $5 \mathrm{ml}$ of sea water in each vial. These vials were then placed under light. After about on day number of survived shrimps were counted by the use of $3 \mathrm{X}$ magnifying glass. Data, thus obtained, was analyzed by probity analysis by the use of $95 \%$ confidence interval [16]. 
DPPH inhibition assay: A $10 \mu \mathrm{l}$ of test solution was added in 96-wells plate followed by the addition of $90 \mu \mathrm{l}$ of $100 \mu \mathrm{M}$ methanol DPPH solution to make total volume up to $100 \mu \mathrm{l}$. The contents were mixed and incubated at $37^{\circ} \mathrm{C}$ for $30 \mathrm{~min}$. The reduction in the absorbance was measured at $517 \mathrm{~nm}$ using Synergy HT BioTek ${ }^{\circledR}$ USA microplate reader. Quercetin was used as standard antioxidant. All experiments were carried out in triplicates. For the determination of IC50 values, test solutions were assayed at various dilutions i.e. $0.5,0.25,0.125$, $0.0625,0.0313,0.015 \mathrm{mM}$. Data obtained was computed on Ezi-fit software [17]. The decrease in absorbance indicates increased radical scavenging activity which was determined by the following formula.

Inhibition $(\%)=\frac{(\text { Abs. of control }- \text { Abs.of test solution })}{A b s . \text { of control }}$ $\times 100$

Where: Absorbance of control=Total enzyme activity without inhibitor, Absorbance of test=Activity in the presence of test compound

\section{Results and Discussion}

The shade dried whole plant of D. ramosa was carried for extraction process through the mechanism of maceration with dichloromethane and methanol sequentially. The extraction results, along with their assigned codes used are given in Table 1.

For the purpose of detection of alkaloids, tests were done by using Mayer s reagents, Wagner s reagents, Hager's reagents and Dragendroff's reagents. Keller kiliani test was done for detection of cardiac glycosides. The chemical test for detection of saponins was performed. The obtained results are given in Table 2.

Results of total phenolic, flavonoid and alkaloid content are summarized in Table 3. Methanol extract exhibited higher phenolic content as compared to the dichloromethane extract. While dichloromethane extract showed high flavonoid and alkaloid contents. Values are expressed as mean \pm SEM of triplicate measurements.

Table 1. Results of extraction of D. ramosa with dichloromethane and methanol.

\begin{tabular}{lllll}
\hline Plant name & Part used & Solvent used & Extract codes & Weight of extracts (gm) \\
\hline D. ramosa & Whole plant & Dichloromethane & DRD & $23 \mathrm{gm}$ \\
\hline & & Methanol & DRM & $38 \mathrm{gm}$ \\
\hline
\end{tabular}

Table 2. Results of detection of secondary metabolites from the whole plants of D. ramosa.

\begin{tabular}{|c|c|c|c|c|c|c|}
\hline Secondary metabolites & Alkaloids & Cardiac glycosides & Saponins & Tannins & Terpenoids & Flavonoids \\
\hline Status & + & + & + & - & + & + \\
\hline
\end{tabular}

Table 3. Total phenol, flavonoid and alkaloid content of dichloromethane and methanol extracts of D. ramosa.

\begin{tabular}{|c|c|c|c|}
\hline \multirow{2}{*}{ Plant extract code } & TPC & TFC & Alkaloid content \\
\hline & (mg of ${ }^{*} \mathrm{GA} / \mathrm{g}$ extract) & (mg of ${ }^{* *} \mathrm{RE} / \mathrm{g}$ extract) & (mg of ${ }^{* * *} \mathrm{AE} / \mathrm{g}$ extract) \\
\hline DRM & $199.2 \pm 4.50$ & $50.13 \pm 3.51$ & $23.92 \pm 1.52$ \\
\hline DRD & $184.2 \pm 4.04$ & $73.02 \pm 1.00$ & $29.73 \pm 4.04$ \\
\hline
\end{tabular}

Values are expressed as mean \pm SEM of triplicate measurements.

${ }^{*} \mathrm{GA}$ : Gallic acid; ${ }^{* *} \mathrm{RE}$ : Rutin, ${ }^{* * *} \mathrm{AE}$ : Atropine

Results of identification and quantification of phenolic contents by HPLC showed the presence of chlorogenic acid, benzoic acid, ferulic acid, quercetin, syringic acid and vanillic acid in dichloromethane extract. Whereas caffeic acid, chlorogenic acid, cinnamic acid, gallic acid, p-coumaric acid, $\mathrm{m}$-coumaric acid, quercetin, syringic acid and vanillic acid was present in methanol extract. Tables 4 and 5 show the retention time, area (mV.s), area $(\%)$ and concentration of the various phenolic compounds found in methanol and dicholoromehane extracts respectively.

Brine shrimp (Artemiasalina) lethality bioassay was carried out against both dichloromethane and methanol extracts of $D$. ramosa for cytotoxic evaluation. Dichloromethane extract exhibited a very significant cytotoxic activity with "LD50 
$0.6903 \mu \mathrm{g} / \mathrm{ml}$ ”. No cytotoxic activity was showed by methanol extract. Results are given in Table 6.

Table 4. Identification and quantification of methanol extract of D. ramosa.

\begin{tabular}{|c|c|c|c|c|c|}
\hline S.No. & Name of compounds & Retention time (min) & Area (mV.s) & Area (\%) & Concentration (ppm) \\
\hline 1 & Caffeic acid & 12.2 & 39.313 & 4.3 & 1.81 \\
\hline 2 & Chlorogenic acid & 15.42 & 8.344 & 0.9 & 0.64 \\
\hline 3 & Cinnamic acid & 26.247 & 30.625 & 3.4 & 0.39 \\
\hline 4 & Gallic acid & 4.867 & 17.769 & 2 & 0.63 \\
\hline 5 & m-coumaric acid & 20.34 & 25.159 & 2.8 & 0.31 \\
\hline 6 & p-coumaric acid & 17.32 & 7.619 & 0.8 & 0.09 \\
\hline 7 & Quercetin & 3.213 & 36.456 & 4 & 1.92 \\
\hline 8 & Syringic acid & 16.3 & 51.854 & 5.7 & 1.29 \\
\hline 9 & Vanillic acid & 13.66 & 49.736 & 5.5 & 3.81 \\
\hline
\end{tabular}

Table 5. Identification and quantification of dichloromethane extract of D. ramosa.

\begin{tabular}{|c|c|c|c|c|c|}
\hline S.No. & Name of compounds & Retention time & Area (mV.s) & Area (\%) & Concentartion (ppm) \\
\hline 1 & Chlorogenic acid & 15.92 & 24.615 & 2.3 & 2.69 \\
\hline 2 & Benzoic acid & 14.807 & 52.176 & 4.9 & 5.51 \\
\hline 3 & Ferulic acid & 22.6 & 21.104 & 2 & $1.51 \mathrm{~s}$ \\
\hline 4 & Quercitin & 3.127 & 29.818 & 2.8 & 1.57 \\
\hline 5 & Syringic acid & 16.753 & 92.278 & 8.6 & 2.35 \\
\hline 6 & Vanillic acid & 13.773 & 28.877 & 2.7 & 1.78 \\
\hline
\end{tabular}

Table 6. Results of Brine shrimp (Artemiasalina) Lethality bioassay of dichloromethane and methanol extract of whole plant of D. ramosa.

\begin{tabular}{|c|c|c|c|c|c|c|}
\hline Extract code & Dose (ug/ml) & No. of shrimps & No. of survivors & LD50 (ug/ml) & Standard drug & LD50 (ug/ml) \\
\hline & 1000 & 30 & 0 & & & \\
\hline & 100 & 30 & 2 & & & \\
\hline \multirow[t]{3}{*}{ DRD } & 10 & 30 & 6 & 0.6903 & Etoposide & 7.4625 \\
\hline & 1000 & 30 & 22 & & & \\
\hline & 100 & 30 & 28 & & & \\
\hline DRM & 10 & 30 & 29 & 10246.36 & Etoposide & 7.4625 \\
\hline
\end{tabular}

Table 7 represent the antioxidant activity of dichloromethane and methanol extracts of D. ramosa. Dichloromethane extract showed 55.37s $\pm 3.055 \mathrm{DPPH}(\%)$ inhibition \pm SEM while methanol extract showed $72.76 \pm 1.52 \mathrm{DPPH}(\%)$ inhibition \pm SEM.

Herbal plants rich in phenolic compounds are progressively being utilized in food industry due to their retarding effect on oxidative degradation of lipids as well as can improve the nutritional value and quality of food [18].

Table 7. DPPH \%inhibition of dichloromethane and methanol extract of D. ramosa.

\begin{tabular}{ll}
\hline Plant extract code & DPPH inhibition (\%) \\
\hline DRM & $72.76 \pm 1.52$ \\
\hline DRD & $55.37 \pm 3.055$ \\
\hline Quercetin (Standard) & $74.54 \pm 1.03$ \\
\hline $\begin{array}{l}\text { Values are expressed as mean } \\
\text { triplicate measurements. }\end{array}$ & \\
\hline
\end{tabular}

Higher total phenolic content was found in the methanol extract $199.2 \pm 4.50(\mathrm{mg}$ of $\mathrm{GA} / \mathrm{g}$ of extract) than that of dichloromethane $184.2 \pm 4.04$ (mg of GA/g of extract). 
Phenolic compounds of plants are categorized into various categories; major among these are flavonoids which have promising antioxidant activities [19]. Flavonoids are naturally present in plants and are known to produce positive effect on human health. Studies have proved that flavonoids have diverse range of antiviral, anti-inflammatory, antibacterial, anti-allergic and anticancer activities [20]. Moreover, flavonoids possess strong scavenging effect on oxidizing molecules like singlet oxygen and various free radicals [21] involved in various diseases. In our study higher flavonoid content was found in dichloromethane extract with $73.02 \pm$ 1.00 (mg of extract) as compared to that of methanol extract having $50.13 \pm 3.51$ ( $\mathrm{mg}$ of RE/g of extract) (Figures 1 and 2).

The electron donating capacity of herbal plants can be determined 2,20-diphenyl-1- picrylhydrazyl radical (DPPH), purple colored solution bleaching. The method is based on the principle that DPPH solution is scavenged and decolorized on the addition of some radical species or antioxidants. The change in color is directly proportional to the concentration of antioxidants. An enormous decrease is observed in the absorbance of reaction mixture which indicates the significant radical scavenging activity of the compound under test [20]. In the present study methanol extract showed higher free radical scavenging activity with $72.76 \pm 1.52 \%$ inhibition of DPPH as compared to the dichloromethane extract showing $55.37 \pm$ $3.055 \%$ inhibition of DPPH. Studies have proved that methanol extract may possess phenolic and hydroxyl-phenolic compounds with alcohol, sugar, acids and glycosides [22]. Higher antioxidant activity of methanol extract of D. ramosa may be due to the presence of these compounds or flavonoids.

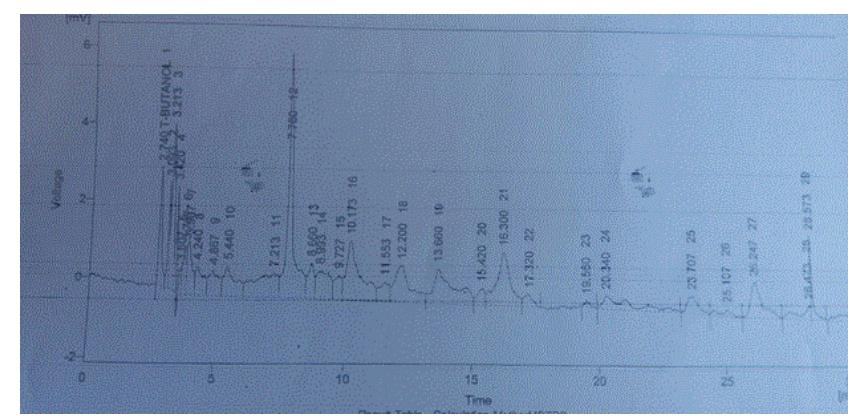

Figure 1. Identification and quantification of phenolic contents of methanol extract of D. ramosa by HPLC

In cytotoxic assay that is carried out through Brine Shrimp (Artemiasalina) Lethality Assay, the DCM extract show very high potential for Cytotoxicity. Results revealed that the LD50 of dichloromethane extract is $0.6903 \mu \mathrm{l} / \mathrm{ml}$ as standardized with Etoposide with LD50 of $7.4625 \mu \mathrm{l} / \mathrm{ml}$. It is concluded that dichloromethane extract of $D$. ramosa is 10 time more potent than Etoposide. Previous studies have proved that some flavonoids like quercetin possesses anticancer activity and inhibited the growth of cancer cells [23]. Gallic acid had free radical scavenging effect and induced apoptosis and differentiation in leukemia, lymphocyte cells, colon adenocarcinoma cell lines and lung cancer [24]. It has been proved that gallic acid have key role in the hindrance of cancer development and malignant transformation just like quercetin.
Thus it may be attributed that plant possesses high cytotoxic effect due to the presence of high flavonoid content in the plant.

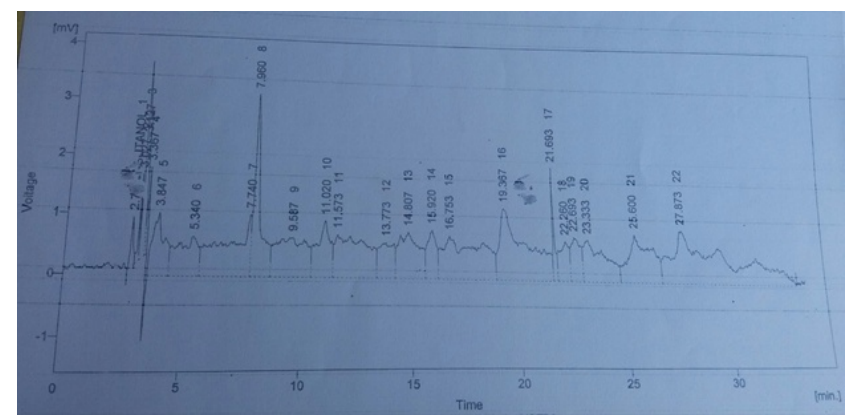

Figure 2. Identification and quantification of phenolic contents of dichloromethane extract of D. ramosa by HPLC.

Alkaloids have diverse range of biological properties involving antibacterial and anticancer activities and thus are responsible for the healing properties of natural medicine [25]. The present study showed the presence of significant level of alkaloids in both extracts. In dichloromethane extract alkaloid content was found to be $29.73 \pm 4.04$ ( $\mathrm{mg}$ of $\mathrm{AE} / \mathrm{g}$ of extract) whereas in methanol extract it was $23.92 \pm 1.52$ (mg of AE/g of extract).

\section{Conclusion}

The present study provides the evidence that the $D$. ramosa have prominent cytotoxic and antioxidant potential due to the presence of higher phenol, flavonoid and alkaloid content in the plant. Future research may be based on systemic investigation, fractionation, purification and isolation of antioxidants and cytotoxic agents for the development of novel, target oriented, more effective antioxidants and cytotoxic agents with safe therapeutic index. Further, work related to the isolation of the active constituents through bioassay-directed fractionation is in progress in our laboratory.

\section{Acknowledgments}

Authors are grateful to Department of Pharmacy, Bahauddin Zakariya University, Multan, Pakistan for providing laboratory facilities to carry out research.

\section{Conflict of Interest}

No conflict of interest associated with this study.

\section{Contribution of Authors}

It is declared that this work was done by the authors named in this article and all liabilities pertaining to claims relating to the content of this article will be borne by them.

\section{References}

1. Halliwell B. Antioxidants: The basics- What they are and how to evaluate them. Adv Pharmacol 1997; 38: 3-20. 
2. Niki E. Assessment of antioxidant capacity in vitro and in vivo. Free Radic Biol Med 2010; 49: 503-15.

3. Hazra B, Biswas S, Mnadal N. Antioxidant and free radical scavenging activity of Spondias pinnata. BMC Complement Altern Med 2008; 8: 63.

4. Kleinsmith LL. Principles Of Cancer Biology 2006. Pearson Benjamin Cummings, San Francisco, California 2006.

5. Reuter S, Gupta SC, Chaturvedi MM, Aggarwal BB. Oxidative stress, inflammation, and cancer: how are they linked? Free Radic Biol Med 2010; 49: 1603-1616.

6. Miller A.L. Antioxidant flavonoids: Structure, function and clinical usage. Altern Med Rev 1996; 1: 103-111.

7. Gulcin I. Antioxidant Activity of Food Constituents: An Overview. Arch Toxicol 2012; 86: 345-391.

8. Ahmad KS, Qureshi R, Hameed M, Ahmad F, Nawaz T. Conservation Assessment and Medicinal Importance of some plants resources from Sharda, Neelum Valley, Azad Jammu and Kashmir, Pakistan Int J Agric Biol 2012; 14: 997.

9. Adnan M, Begum S, Khan AL, Tareen AM, Lee IJ. Medicinal plants and their uses in selected temperate zones of Pakistani Hindukush-Himalaya. J Med Plant Res 2012; 6: 4113-4127.

10. Ahmed E, Arshad M, Ahmad M, Saeed M, Ishaque M. Ethnopharmacological survey of some medicinally important plants of Galliyat Areas of NWFP, Pakistan. Asian J Plant Sci 2004; 3: 410-415.

11. Wani MH, Shah MY, Naqshi AR. Medicinal ferns of Kashmir, India Int J Bioassays 2016; 5: 4677-4685.

12. Brain KR, Turner TD. The practical evaluation of pharmaceuticals 1983. Wright Scientechnica Publishers, Bristol, England 1975.

13. Ainsworth EA, Gillespie KM. Estimation of total phenolic content and other oxidation substrates in plant tissues using Folin-Ciocalteu reagent. Nat Protoc 2007; 2: 875.

14. Zhishen J, Mengcheng T, Jianming W. The Determination of flavonoid contents in mulberry and their scavenging effects on superoxide radicals. Food Chem 1999; 31: 555 -559 .

15. Fazel S, Hamidreza M, Rouhollah G, Mohammadreza V. Spectrophotometric determination of total alkaloids in some Iranian medicinal plants. Thai J Pharm Sci 2008; 32: 17-20.
16. Rahman A, Chaudhary MI, Thomsen WJ. Bioassay techniques for drug development 2001. Harwood academic publishers, Canada.

17. Alhakmani F, Kumar S, Khan SA. Estimation of total phenolic content, in-vitro antioxidant and antiinflammatory activity of flowers of Moringa oleifera. Asian Pac J Trop Biomed 2013; 3: 623.

18. Rao TM, Rao BG, Rao YV. Antioxidant activity of Spilanthes acmella extracts. Inter Jour of Phytopharm 2012; 3: 216-20.

19. Naczk M, Shahidi F. Extraction and analysis of phenolics in food. J Chromatogr A 2004; 1054: 95-111.

20. Nunes PX, Silva SF, Guedes RJ, Almeida S. Biological oxidations and antioxidant activity of natural products, Phytochemicals as nutraceuticals Global Approaches to Their Role in Nutrition and Health 2012. Toronto.

21. Montoro P, Braca A, Pizza C, De Tommasi N. Structureantioxidant activity relationships of flavonoids isolated from different plant species. Food Chem 1998; 92: 349.

22. Krishnaiah D, Sarbatly R, Nithyanandam R. A review of the antioxidant potential of medicinal plant species. Food Bioprod Process 2011; 89: 217-233.22.

23. Kikuzaki H, Nakatani N. Antioxidant Effects of Some Ginger Constituents. J Food Sci 1993; 58: 1407-1410.

24. Inoue M, Suzuki R, Koide T, Sakaguchi N, Ogihara Y, Yabu Y. Antioxidant, gallic acid, induces apoptosis in HL-60RG cells. Res. Commun 1994; 204: 898-904.

25. Nithya TG, Jayanthi J, Ragunathan MG. Antioxidant activity, total phenol, flavonoid, alkaloid, tannin, and saponin contents of leaf extracts of Salvinia molesta DS Mitchell. Asian J Pharm Clin Res 1972; 9: 200-203.

\section{*Correspondence to}

Baloch R

Department of Pharmaceutical Chemistry

Bahauddin Zakariya University

Multan

Pakistan 